a different aetiology from the hitherto accepted theories propounded by Knie and Weber, i.e., it is a matter of a too abundant secretion of aqueous fluid in comparison to its means of drainage rather than of a clogging of the anterior drainage. But other possibilities must also be considered. Let us be satisfied with the fact that the C.D.P. can be of use in the severest cases of glaucoma.

\title{
AMBLYOPIA EX ANOPSIA IN CHILDREN
}

BY

\section{J. HORTON YOUNG}

CHELMSFORD

\section{A New Type of Ventilating Occluder}

Amblyopia ex anopsia in children is an ever growing practical problem. Among the school children of Essex there are approximately 2,500 "squinting " children, this total including only those children who come directly under the control of the Essex County Council Ophthalmic Service, and excludes those cases which are to be found within the autonomous borough councils. When one considers the problem from a national angle the total number of "squinting" children must reach staggering proportions. The incidence of " squint " appears to be increasing.

School children in this country are not all treated by ophthalmic surgeons and the result is that amblyopia must predominate in those areas where this specialised service is not available, although it would be very wrong to state that it was limited to these areas.

The fact is that most parents are not sufficiently well informed in a lay sense on the disabilities resulting from " squint," that many school medical officers are completely ignorant of the urgent necessity of getting the amblyopic eye to " see" as soon as possible, and that those who do attempt to counteract the amblyopia become discouraged when the instruments, which they are asked to use, break down in practice. The average medical officer finds it hard to decide when amblyopia is present in younger children. Moreover, the practice of not doing a post-retinoscopic subjective test is still very prevalent.

Also a satisfactory occluder for these cases has not been designed, although much time and patience have been put into this problem, as is evidenced by the numerous types of occluder to be found on the market, each in its turn attempting to counteract the disadvantages of previous models.

To aggravate the problem a great number of these " squinting " children are not detected until they reach the infants' department 
of the elementary school, and in many cases not until the children have had their second full examination at eight years of age. At this stage they usually have a well-established amblyopia. Strenuous efforts are being made through the child welfare centres and the toddlers' clinics to get the cases earlier. The first six months of a child's school career is the period during which some of the most intractable "squints" develop. These children of four years and upwards, being active and inquisitive are poor co-operators when occlusion is attempted, for this, depriving them of their visual acuity, virtually renders them blind persons for a period, renders them prone to accident and subjects them to such a restriction of activity, that their childish natures, not comprehending the necessity for treatment, revolt. Is it any wonder then that "peeping" is a common feature of " squint" cases, when month after month the vision remains unimproved, until in desperation the oculist orders a complete " black-out " with elastoplast or some other medium. But this is impracticable, for the dressing has to be replaced every week, is unhygienic, uncomfortable, and entails considerable expense and inconvenience to parents. Parents co-operate badly under such conditions.

In an endeavour to settle the problem from all points of view, I decided to design an occluder to deal with the difficult cases of four years and upwards. The result is an occluder of a new type called an "AERO-Occluder," details of which are given below. Photographs of the instrument are to be seen in Figs. 1 and 2.

The " AERO-OCCLUder " has been designed for permanent total occlusion over a period of six weeks or more. This new occluder is a composite structure of xylo and rubber. The xylo portion consists of a circular perforated basal plate " $\mathrm{B}$ " (available in three sizes, 34, 36, 38 mms. diameter) easily trimmed to fit the frame " D," which takes the place of the spectacle lens before the non-amblyopic eye. The spectacle lens is retained by the dispensing optician until the period of occlusion is finished. A small box "BP" with lateral vents "VV" is attached to this basal plate " B" posteriorly - the ventilating unit. A rubber lateral occluding wing " $\mathrm{W}$ " is fixed to this box " $\mathrm{BP}$ " by a flange " $F$ " which keeps the rubber wing pressed against the perforated basal plate " $\mathrm{B}$," and permits the vents " VV" to open into the rubber cup formed by the rubber occluding wing "W." The medial edge of the rubber wing is thinned and extended so that it passes well on to the bridge of the nose. This prevents peeping.

When the "AERO-Occluder" is in position on the child's face, air passes through the perforations " $\mathrm{B}$ " in the basal plate " $\mathrm{BP}$," through the vents " $\mathrm{VV}$ " and circulates around the eye. The more the child runs about the greater the ventilation. 


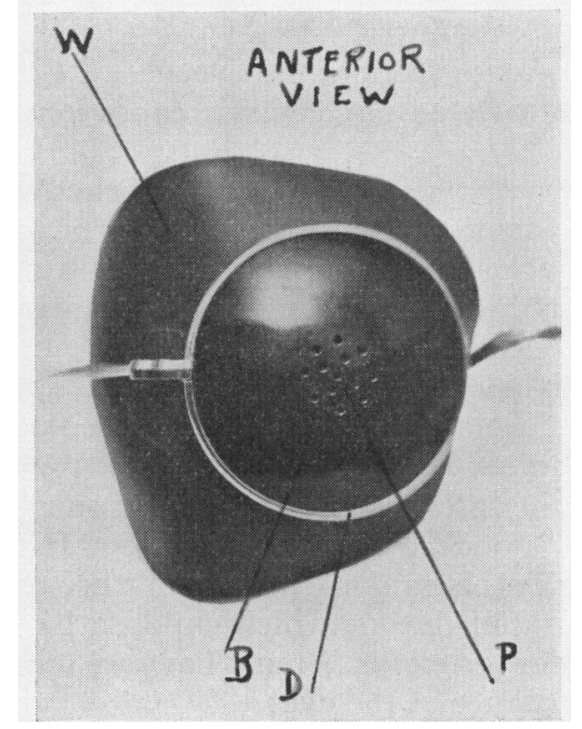

FIG. 1.

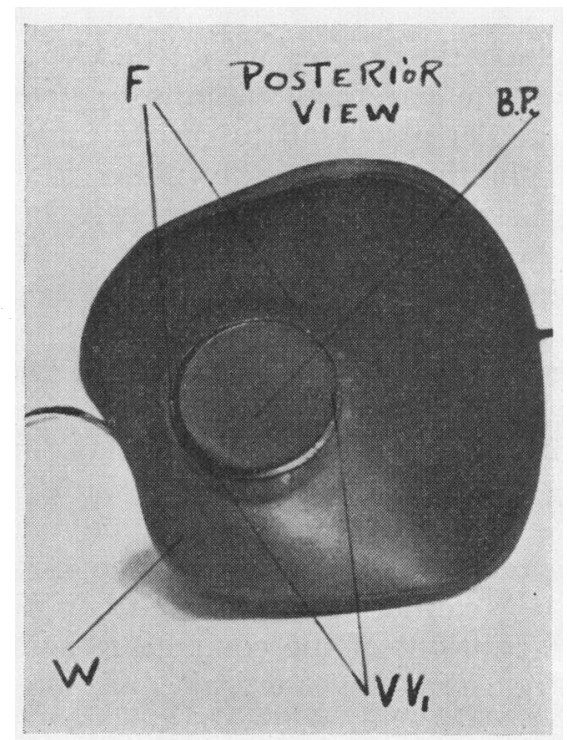

FIG. 2.

The base of the ventilating box " $\mathrm{BP}$ " is the baffle plate whereby the child is prevented from looking through the perforations "P." Complete occlusion is assured and the unique 
ventilating system prevents the heating effect of other occluders with its attendant discomfort.

Theoretically speaking certain other types of occluder appear to be quite sound until tested under clinic conditions when they fail badly.

With the fixed cup type of occluder attached to the spectacle frame behind the lens, it is a common thing to find that this deforms the spectacles and that an accurate fitting is difficult to obtain. Moreover the children, by slightly moving the frame or the occluder, are easily enabled to peep between the side of the nose and the medial side of the occluder.

These children develop a characteristic poise such that the chin is thrown to the same side as the occluded eye, the head is inclined slightly forward, the forehead dropped and turned in the direction of the gaze of the "good" eye which is released from its occlusion. These children may be said to have an "occluder torticollis." Considering the period during which children have to wear these occluders " occluder torticollis" must have an unfavourable effect upon the muscle balance of the eyes.

The rubber sucker types of occluder also have their draw-backs and, while they give satisfactory occlusion, are apt to " sweat" excessively, are readily detachable by the children or parents with the possibility of being replaced later on the wrong eye. Moreover they may detach themselves while the children are at play and get lost, when the parent often fails to get them replaced. These types of occluder also tend to displace the spectacle from the nose, owing to the thickness of the rubber wing on the medial side, and the large size of sucker attachment.

It is to combat this loss of efficiency that the "AERO-OCCLUDER" replaces the lens in the spectacle frame. As a result the children are offered two alternatives only, either to wear the spectacles with its fixed occluder or to leave them off altogether. As these children are usually fairly hypermetropic they feel the need of spectacles, and the immediate result is an improvement in vision in the " sqinting" eye. Failure to improve in vision indicates one of two things: (1) non-co-operation; (2) some pathological state previously overlooked. The remedy is then obvious, since the "AERO-OCCLUDER" cannot be interfered with except by the express order (prescription) of the consulting oculist.

It will be seen then that the practical conditions governing the choice of an occluder are of considerable importance.

The rate of improvement of vision in the amblyopic eye depends mainly on the age of the child, those children under four years of age developing alternation (cover test) and ability to see Worth's ivory balls within six weeks. Indeed in these young children one may get a reversal of vision such that the non- 
amblyopic eye becomes the amblyopic one. This reversal is rarely seen in children of five years and over, as the macular perceptions become more stable. It is true that a temporary diminution may be found in some cases but the full visual acuity comes back if occlusion is discontinued for a few days. The " master" eye appears to have "priority" like being righthanded or left-handed, as it were, although there appears to be no definite relationship in squinting cases as regards the " master" eye and right or left-handedness.

When alternation has been proved in a young child it is better to maintain alternating daily occlusion for some time in order to " stabilize" the alternation since in this way the visual acuity is preserved in each eye. A simple flat " clip on" disc type of occluder is all that is required for this purpose. The visual acuity, however, remains the criterion on which any treatment is carried out.

With children of four years and upwards the rate of improvement is one to one and a half lines of Snellen's types per month, as judged by those children who can read letters, but the younger members of this age group will have to be tested by the "Cors", test, e.g.,

$\begin{array}{lllll} & & & & \text { Approx. } \\ \text { A penny equals } \ldots & \ldots & \ldots & \ldots & 6 / 18 \\ \text { A halfpenny equals } & \ldots & \ldots & \ldots & 6 / 12 \\ \text { A sixpence equals } & \ldots & \ldots & \ldots & 6 / 9\end{array}$

or other appropriate children's visual acuity test.

One should remember that a subjective test in children has its limitations in that any test performed is only accurate within the limits of the child's psychology, its intellectual advancement, and its emotional " make-up" (viz., its precociousness). Money, however, by playing upon the material instincts of the children, seems to conquer any backwardness, more especially if a child under examination is promised a halfpenny if he or she can select the coins correctly. This " coin " test is fairly accurate within the limits of the visual angles required in Snellen's test types and works out in practice very well. The children judge by size and colour of coins and not by the inscriptions. If non-recognition is present, the parent is advised to teach the child the difference between the coins before coming to visit the oculist at his next clinic.

Messrs. Alfred Hawes and Son are the makers of this instrument. I am indebted to them for their helpful co-operation and suggestions. 